\title{
ORIGINAL RESEARCH \\ Distinguishing between Germinomas and Pineal Cell Tumors on MR Imaging
}

N. Dumrongpisutikul

J. Intrapiromkul

D.M. Yousem

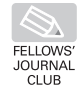

BACKGROUND AND PURPOSE: Tumors of pineal cell origin have different prognosis and treatment than those of germ cell origin. The recent literature suggests that these tumors often look alike. Our study aimed to differentiate between pineal cell tumor and germinoma based on ADC values, the homogeneity of the mass, and MR imaging characteristics.

MATERIALS AND METHODS: We enrolled 20 patients who had pretreatment MR imaging scans with histologic verification of tumors of pineal cell origin and germinomas. The tumors were measured for the ADC values and for homogeneity by the coefficient of variation of ADC values, and T1WI and T2WI signal intensity values.

RESULTS: The 20 subjects (8 females and 12 males) ranged in age from 1.5-64.9 years, with a mean age of 23.9 years (SD 17.7 years). The mean age of those with germinomas was 13.7 years (SD 3.8 years), less than the mean of 29.4 years for those with pineal cell tumors (SD 19.9 years; $P=.016$ ). These 2 groups showed no significant difference in coefficients of variation on T1WI, T2WI, and ADC images. However, germinomas showed statistically significant higher ADC values (mean $1590.69 \pm$ $532.96 \times 10^{-6} \mathrm{~mm}^{2} / \mathrm{s}$ ) than pineal cell tumors (mean $883.58 \pm 317.48 \times 10^{-6} \mathrm{~mm}^{2} / \mathrm{s} ; P=.02$ ). An accuracy of $89.5 \%$, sensitivity of $83.3 \%$, specificity of $92.3 \%$, PPV of $83.3 \%$, and NPV of $92.3 \%$ were yielded for an ADC threshold of $1250.00 \times 10^{-6} \mathrm{~mm}^{2} / \mathrm{s}$.

CONCLUSIONS: Germinomas showed higher ADC values than the pineal cell tumors $(P=.02)$, and the patients were younger. Otherwise, there were no definitive imaging characteristics that distinguished pineal cell tumors from germinomas.

ABBREVIATIONS: NPV = negative predictive value; PNET = primitive neuroectodermal tumor; PPTID = pineal parenchymal tumor of intermediate differentiation; PPV = positive predictive value; PTPR = papillary tumor of the pineal region; TR/TE = repetition time/time-to-echo; $W H O=$ World Health Organization

$\mathbf{P}$ ineal region tumors constitute $1 \%$ of all intracranial tumors $^{1}$ and account for $3 \%-8 \%$ of intracranial tumors in children. ${ }^{2}$ Among the various histologic types of pineal tumors, germinomas are the most frequent, followed by teratomas. The germ cell tumors constitute approximately $35 \%{ }^{3}$ of all pineal region tumors. The pineal cell origin tumors, that is, pineoblastoma and pineocytoma, are less frequently seen (approximately $28 \%$ of the total $)^{3}$ and are believed to be differentiated from other cell types by their characteristic dispersion rather than engulfment of the pineal calcifications, as seen in germinomas. The imaging literature suggests that the common pineal region tumors have no pathognomonic imaging patterns. ${ }^{4}$ In addition, approximately $11 \%$ of biopsies are either nondiagnostic or misdiagnosed ${ }^{5}$ due to the complexity of the masses and their high vascularity, leading to insufficient tissue.

Because of the overlapping imaging findings on conventional techniques, scanning may be less useful than serum markers for differential diagnosis specificity. DWI is an imaging technique that has been applied for evaluation of cerebral infarction, ${ }^{6,7}$ glioma and lymphoma, ${ }^{8-10}$ and brain

Received February 15, 2011; accepted after revision June 24.

From the Department of Radiology (N.D., J.I., D.M.Y.), The Johns Hopkins Medical Institution, Baltimore, Maryland, and Department of Radiology (N.D.), King Chulalongkorn Memorial Hospital, Pathumwan, Bangkok, Thailand.

Please address correspondence to David M. Yousem, MD, MBA, Department of Radiology, The Johns Hopkins Medical Institution, 600 N. Wolfe St, Phipps B100F, Baltimore, MD 21287; e-mail: dyousem1@jhu.edu

http://dx.doi.org/10.3174/ajnr.A2806 abscesses ${ }^{11,12}$ because it provides image contrast based on molecular (Brownian) motion of water. ${ }^{6,13}$ ADC values generated from DWI can imply the relative intracellular and extracellular volumes within the tissue being studied..$^{8-10}$ However, information on the diffusivity of pineal tumors is limited. With the wide clinical availability of DWI, measurements of ADC values are more frequently integrated into conventional imaging analysis and may help differentiate between germinomas and pineal cell tumors. In addition, we have anecdotally observed that germinomas tend to be more homogeneous in MR signal intensity than other tumors.

Because there is a difference between the prognosis and treatment of tumors of pineal cell origin and those of germ cell origin, our study aimed to differentiate between pineal cell tumors and germinomas based on ADC values, the homogeneity of the mass, and other MR imaging characteristics.

\section{Materials and Methods}

We enrolled 20 patients with histologic verification of a pineal cell origin tumor and germinoma from our institute by using query keywords of the Radiology Information System and pathology data base for "pineoblastoma," "pineocytoma," and "germinoma" during a query period from 2002-2010. In this study we excluded patients with previous surgical resection or histopathologic reports outside our hospital. Demographic data were recorded from the electronic medical record. MR imaging studies were retrospectively reviewed and measured for the ADC values and for homogeneity by measuring the standard deviation divided by the means of ADC values, T1WI, and T2WI, measured by a standard ROI analysis from PACS. Specifically, 

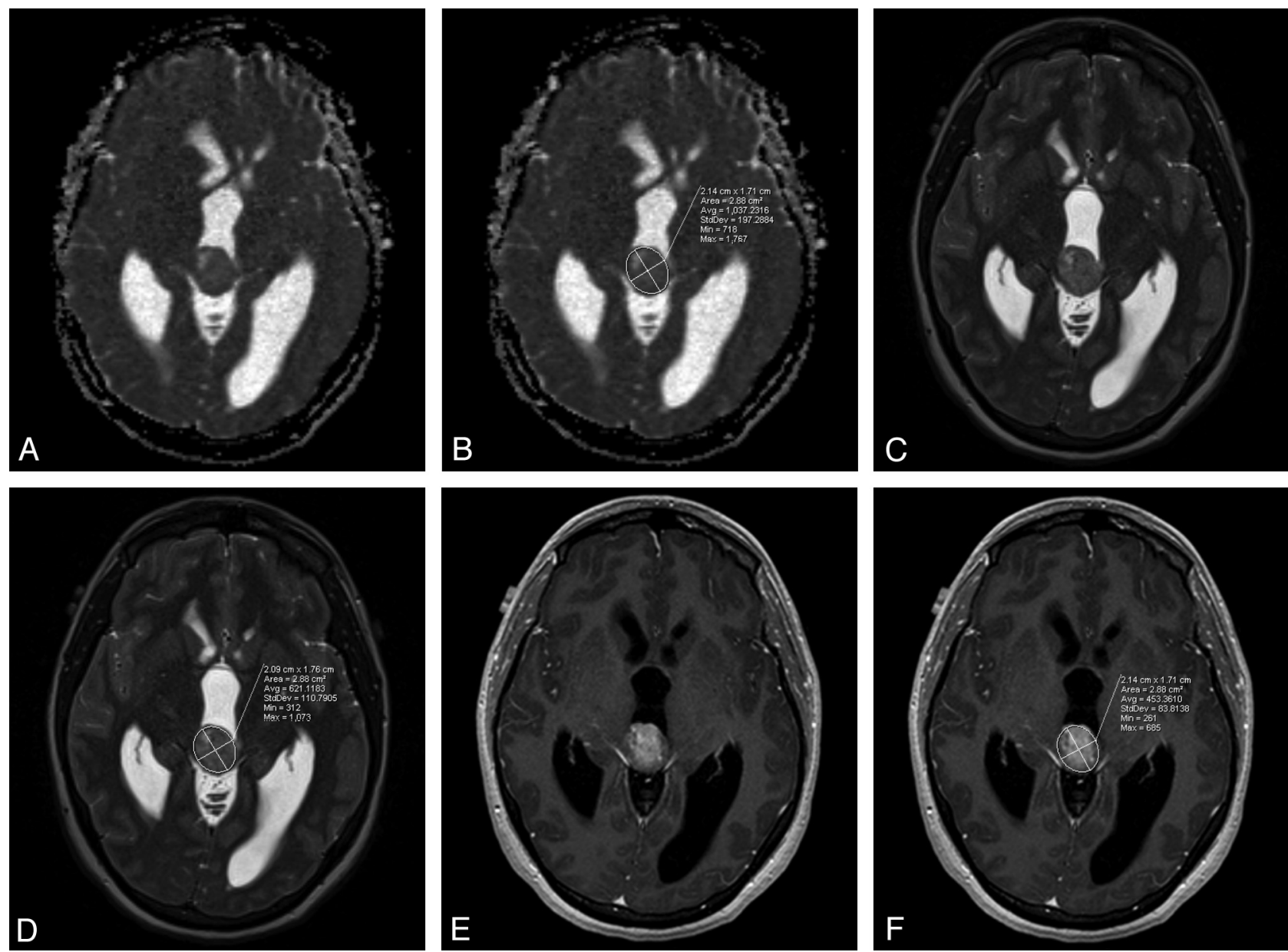

Fig 1. $A D C$ map $(A)$ with region of interest drawn $(B)$, T2-weighted image $(C)$ with region of interest drawn $(D)$, and postcontrast T1-weighted image $(E)$ with region of interest $(F)$ are seen in this papillary tumor of the pineal gland. The standard deviations were divided by the means to obtain coefficients of variation.

we used elliptical ROIs that included the entire tumor. We then assessed the percentage of solid to cystic components of the mass by dividing the area of the cystic portion by the area of the entire mass on the axial scan that showed the greatest dimension of the mass.

The scans were also evaluated qualitatively for enhancement degree (mild [faint], moderate [intermediate], and marked [as much as expected for a meningioma] based on observation) and pattern. A diagnosis was also predicted based on overall nonquantitative imaging characteristics by the most experienced ( 22 years) neuroradiologist author, blinded to the age of the patient.

\section{Imaging Techniques}

The MR studies were performed with different MR scanners: 15 with a 1.5T (Signa HDx; GE Healthcare, Milwaukee, Wisconsin), 1 with a $3 \mathrm{~T}$ Trio, and 4 with a $1.5 \mathrm{~T}$ Avanto scanner (both Siemens Medical Systems, Erlangen, Germany). Nineteen patients were scanned using a $1.5 \mathrm{~T}$ magnet, and 1 with a $3 \mathrm{~T}$ magnet. In addition to axial DWI, conventional T1WI, T2WI, FLAIR, and postgadolinium images were performed. Three neuroradiologists retrospectively reviewed the images without information of the pathologic results.

The sagittal T1WIs were performed with the following parameters: the range of TR 9.89-696 ms/TE 4.6-14 ms; matrix size of $192 \times$ 192 to $512 \times 196$; FOV of $190 \times 190 \mathrm{~mm}$ to $240 \times 240 \mathrm{~mm}$; and section thickness/spacing of $1-\mathrm{mm} / 1-\mathrm{mm}$ to $5-\mathrm{mm} / 7-\mathrm{mm}$.

The axial T2WI was performed with the range of TR 2500-7000
ms/TE $83.136-112 \mathrm{~ms}$; matrix size of $256 \times 184$ to $448 \times 335$; FOV of $159 \times 200 \mathrm{~mm}$ to $240 \times 240 \mathrm{~mm}$; and section thickness/spacing of 2-mm/2-mm to $5-\mathrm{mm} / 5-\mathrm{mm}$.

DWI was performed with the EPI sequence with a TR/TE range from $4900-10000 \mathrm{~ms} / 80-133 \mathrm{~ms}, 5-\mathrm{mm}$ thin contiguous sections, an FOV of $220 \times 220 \mathrm{~mm}$ to $240 \times 240 \mathrm{~mm}$, and a matrix size of $96 \times$ 96 to $192 \times 192$. Diffusion was measured in the 6 orthogonal directions with $2 \mathrm{~b}$-values $\left(0\right.$ and 1000 seconds $/ \mathrm{mm}^{2}$ ). In 1 case, we were unable to measure ADC values.

\section{Data Analysis}

The ADC images were obtained by using postprocessing software for each vendor's MR scanner. The ADC values were measured from the RadSuite Advanced Visualization PACS (Emageon, Birmingham, Alabama). ROIs were thoroughly positioned around the border of the tumors by 2 radiologists independently in separate sessions, blinded to the final diagnosis. The regions of interest used an ellipital shape that was deformed to include the entire lesion on the axial scans to match the ADC maps, which were provided in the axial plane (Fig 1). These recorded values included the standard deviations and mean values measured on T1WI, T2WI, and ADC sequences, with heterogeneity assessed by using the coefficient of variation ( $\mathrm{SD} /$ mean). The entire tumor - consisting of the solid, cystic, and calcified areas - was included in the ROI. The lesions were evaluated for cystic component as the portion of the tumor that did not enhance but that had fluid 


\begin{tabular}{lcccccc}
\hline \multicolumn{2}{l}{ Table 1: Age, T1, and T2 signal intensity values of the pineal region tumors } \\
\hline & $\begin{array}{c}\text { Age Range } \\
\text { (years) }\end{array}$ & $\begin{array}{c}\text { Mean Age (years) } \\
\pm \text { SD (years) }\end{array}$ & $\begin{array}{c}\text { T1 Value } \\
\text { Range }\end{array}$ & $\begin{array}{c}\text { Mean } \\
\text { T1 } \pm \text { SD }\end{array}$ & $\begin{array}{c}\text { T2 Value } \\
\text { Range }\end{array}$ & $\begin{array}{c}\text { Mean } \\
\text { T2 } \pm \text { SD }\end{array}$ \\
Tumors & $39.6-64.9$ & $48.7 \pm 14.1$ & $235.89-426.27$ & $305.58 \pm 104.94$ & $616.11-995.52$ & $755.52 \pm 208.75$ \\
Pineocytoma $(n=3)$ & $45.6-47.2$ & $46.4 \pm 1.1$ & $196.13-230.19$ & $213.16 \pm 24.08$ & $321.74-593.47$ & $457.61 \pm 192.14$ \\
PPTID $(n=2)$ & $1.5-31.6$ & $16.6 \pm 21.3$ & $187.92-286.24$ & $237.08 \pm 69.52$ & $437.58-804.67$ & $621.13 \pm 259.57$ \\
PTPR $(n=2)$ & $3.3-45.8$ & $18.3 \pm 15.0$ & $197.90-357.34$ & $282.44 \pm 57.65$ & $232.2-478.97$ & $364.33 \pm 98.34$ \\
Pineoblastoma $(n=6)$ & $9.3-20.6$ & $13.7 \pm 3.9$ & $191.00-433.79$ & $278.6 \pm 90.43$ & $418.49-1297.99$ & $718.21 \pm 294.14$ \\
Germinoma $(n=7)$ & & & & & &
\end{tabular}

\begin{tabular}{|c|c|c|c|c|}
\hline Diagnosis & $\begin{array}{c}\text { Size-AP X transverse } \\
\text { X SI }(\mathrm{cm})\end{array}$ & $\begin{array}{l}\text { Percent } \\
\text { Cystic }\end{array}$ & Hemorrhagic? & $\begin{array}{l}\text { Calcified? (modality } \\
\text { used to assess) }\end{array}$ \\
\hline Pineoblastoma & $4.6 \times 5.9 \times 6.1$ & 5.36 & No & No, CT \\
\hline Pineoblastoma & $2.5 \times 1.8 \times 2.6$ & 0.00 & No & No, CT \\
\hline Pineoblastoma & $2.3 \times 2.0 \times 1.6$ & 0.00 & No & Yes, diffusely, CT \\
\hline Pineoblastoma & $1.7 \times 1.9 \times 1.8$ & 0.00 & No & No, CT \\
\hline Pineoblastoma & $2.5 \times 2.1 \times 2.6$ & 40.38 & No & No, CT \\
\hline Pineoblastoma & $3.3 \times 2.6 \times 4.7$ & 0.00 & No & No, CT \\
\hline Pineocytoma & $2.1 \times 2.1 \times 1.8$ & 48.20 & No & No, MR \\
\hline Pineocytoma & $1.9 \times 1.8 \times 1.3$ & 0.00 & No & No, CT \\
\hline Pineocytoma & $1.7 \times 2.3 \times 1.3$ & 37.21 & No & No, CT \\
\hline Intermediate pineal parenchymal tumor & $1.6 \times 1.7 \times 1.6$ & 0.00 & No & No, CT \\
\hline Intermediate pineal parenchymal tumor & $3.8 \times 2.6 \times 3.8$ & 0.00 & No & No, MR \\
\hline Papillary tumor of the pineal region & $2.1 \times 2.0 \times 2.9$ & 26.53 & No & No, CT \\
\hline Papillary tumor of the pineal region & $2.2 \times 2.1 \times 1.9$ & 0.00 & No & No, MR \\
\hline Germinoma & $3.1 \times 3.7 \times 3.6$ & 0.00 & No & Yes, punctate, CT \\
\hline Germinoma & $2.1 \times 2.6 \times 2.1$ & 23.64 & No & No, CT \\
\hline Germinoma & $2.9 \times 3.1 \times 1.9$ & 40.29 & No & Yes, punctate, CT \\
\hline Germinoma & $2.8 \times 3.8 \times 3.0$ & 0.00 & No & No, CT \\
\hline Germinoma & $2.1 \times 2.3 \times 2.5$ & 0.00 & No & No, CT \\
\hline Germinoma & $2.2 \times 1.5 \times 1.6$ & 15.38 & No & No, MR \\
\hline Germinoma & $0.8 \times 0.8 \times 0.7$ & 0.00 & No & No, MR \\
\hline
\end{tabular}

Note:-AP indicates anteroposterior; SI, signal intensity.

signal intensity on the other pulse sequences. The area of maximal cystic component on the axial scan was divided by the maximal overall area on the axial scans for the tumor to determine percentage cystic. If there was $>20 \%$ difference in the measurements of ADC, T1WI, or T2WI values between 2 primary readers, a third independent radiologist remeasured the lesions, blinded to the final diagnosis, to establish the consensus value, which was averaged with its nearest neighbor to create a final mean value. Enhancement characteristics were also recorded as homogeneous or heterogeneous enhancement, and mild, moderate, and marked in degree as described.

\section{Statistical Analysis}

Statistical analyses were performed with SPSS software version 18 (SPSS, Chicago, Illinois). The study of age and coefficient of variation of the mean signal intensity values on T1WI, T2WI, and ADC between germinomas and pineal parenchymal tumors were evaluated by using the $t$ test for independent samples, which was also applied to calculate whether these tumor groups showed significant differences according to different ADC values. A $P$ value of less than 0.05 was considered to indicate a significant difference. Qualitative description of the enhancement degree and pattern were reported as a percentage.

\section{Results}

The 20 subjects ( 8 females and 12 males) ranged in age from 1.5-64.9 years, with a mean age of 23.9 years (SD 17.7 years). The mean age of patients with germinomas was 13.7 years (SD 3.8 years), less than the mean of 29.4 years for patients with pineal cell tumors (SD 19.9 years; $P=.016$; Table 1 ). All pa- tients with germinoma were less than 21 years old. The histopathologic diagnoses were pineocytoma (3 cases), pineoblastoma (6 cases), germinoma ( 7 cases), intermediate pineal parenchymal tumors (2 cases), and papillary tumors ( 2 cases). The size of the germinomas ranged from maximal dimension of 0.8 to $3.8 \mathrm{~cm}$, with a mean of 2.64 (SD 1.01). The pineal cell tumors ranged in maximal dimension from 1.7 to $6.1 \mathrm{~cm}$, with a mean of $2.85 \mathrm{~cm}$ (SD 1.3). The differences in sizes were not statistically significant.

Diffuse tumoral calcification was present in only 1 case, a pineoblastoma, which showed an ADC value of 622.5, the fourth lowest in the sample. Two tumors had a punctate area of 2-mm calcification in a much larger mass. No tumors showed preoperative hemorrhage (Table 2).

The groups showed no significant difference in coefficients of variation on T1WI, T2WI, and ADC images as the assessment of homogeneity (Tables 1 and 3). However, germinomas showed statistically significant higher ADC values (mean $1590.69 \times 10^{-6} \mathrm{~mm}^{2} / \mathrm{s}$, SD $532.96 \times 10^{-6} \mathrm{~mm}^{2} / \mathrm{s}$ ) than pineal cell tumors (mean $883.58 \times 10^{-6} \mathrm{~mm}^{2} / \mathrm{s}$, SD $317.48 \times$ $10^{-6} \mathrm{~mm}^{2} / \mathrm{s} ; P=.02$; Table 4 , Figs 2 and 3 ). If an ADC threshold of $1250.00 \times 10^{-6} \mathrm{~mm}^{2} / \mathrm{s}$ was set such that all germinomas were predicted to be higher and all pineal cell tumors lower, this value yielded an accuracy of $89.5 \%$ (17/19), sensitivity of $83.3 \%$ (5/6), specificity of $92.3 \%$ (12/13), PPV of $83.3 \%(5 / 6)$, and NPV of $92.3 \%(12 / 13)$.

The degree of enhancement of germinomas was mild $(4 / 7=57.1 \%)$, moderate $(1 / 7=14.3 \%)$, and marked $(2 / 7=$ 

Table 3: Coefficient of variation (CV) of T1 and T2 signal intensity
values and ADC values of the pineal region tumors

\begin{tabular}{lccc}
\hline & $\begin{array}{c}\text { Pineal } \\
\text { Parenchymal } \\
\text { Tumors }(n=13)\end{array}$ & $\begin{array}{c}\text { Germinoma } \\
(n=6)\end{array}$ & $P$ \\
\hline $\begin{array}{c}\text { Percentage of CV of T1 } \\
\text { signal value } \pm \text { SD }\end{array}$ & $11.14 \pm 4.57$ & $11.71 \pm 5.24$ & 0.814 \\
$\begin{array}{c}\text { Percentage of CV of T2 } \\
\text { signal value } \pm \text { SD }\end{array}$ & $26.71 \pm 15.17$ & $23.19 \pm 7.41$ & 0.496 \\
$\begin{array}{c}\text { Percentage of CV of ADC } \\
\text { signal value } \pm \text { SD }\end{array}$ & $28.79 \pm 15.63$ & $23.64 \pm 15.03$ & 0.51 \\
\hline
\end{tabular}

\begin{tabular}{lcc}
\hline \multicolumn{3}{l}{ Table 4: ADC values of the pineal region tumors } \\
\hline & $\begin{array}{c}\text { Range ADC } \times \\
10^{-6} \mathrm{~mm}^{2} / \mathrm{s}\end{array}$ & $\begin{array}{c}\text { Mean } \mathrm{ADC} \times 10^{-6} \\
\mathrm{~mm}^{2} / \mathrm{s} \pm \mathrm{SD} \times \\
10^{-6} \mathrm{~mm}^{2} / \mathrm{s}\end{array}$ \\
Tumors & $1123.63-1229.56$ & $1180.34 \pm 53.36$ \\
Pineocytoma $(n=3)$ & $904.14-1067.35$ & $985.75 \pm 115.41$ \\
PPTID $(n=2)$ & $993.25-1296.42$ & $1144.83 \pm 214.37$ \\
PTPR $(n=2)$ & $375.63-1027.49$ & $614.06 \pm 239.65$ \\
Pineoblastoma $(n=6)$ & $1168.49-2637.00$ & $1590.69 \pm 532.96$ \\
\hline
\end{tabular}

* One germinoma was not able to be assessed.

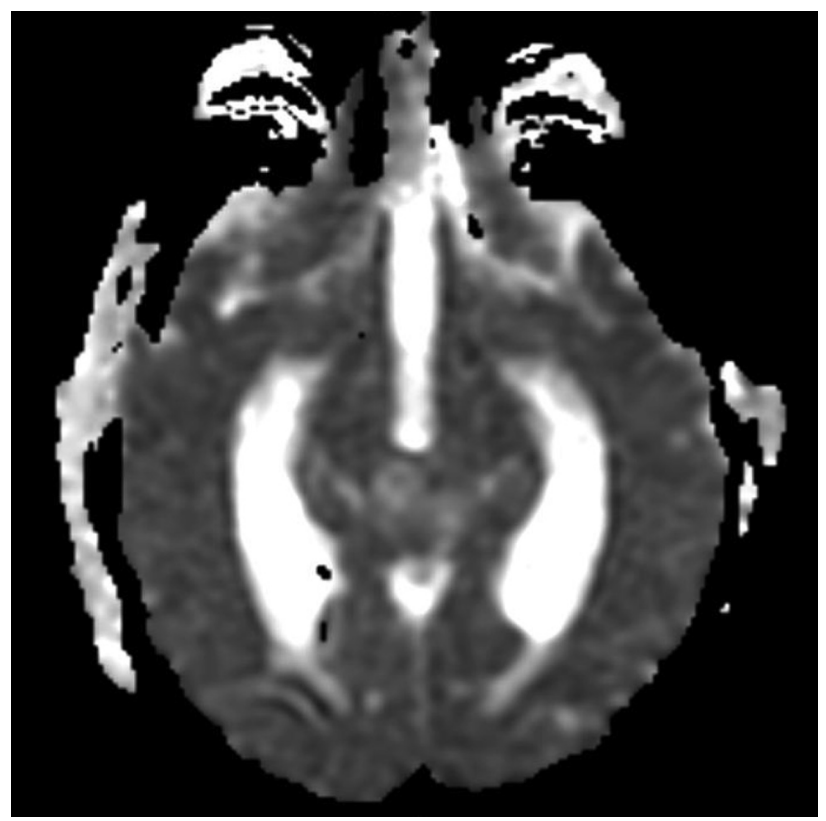

Fig 2. Germinoma shows ADC value of $1500.68 \times 10^{-6} \mathrm{~mm}^{2} / \mathrm{s}$.

$28.6 \%)$, and pineal parenchymal tumors were graded as mild $(4 / 13=30.8 \%)$, moderate $(5 / 13=38.5 \%)$, and marked $(4 / 13=30.8 \%)$. Most of both types of tumors were categorized as heterogeneous in enhancement $(5 / 7=71.4 \%$ for germinomas; $9 / 13=69.2 \%$ for pineal parenchymal tumors).

The masses were homogeneously solid in 12 cases ( 8 pineal cell tumors and 4 germinomas). The 4 tumors that had the greatest percentage of cystic components were 3 pineal cell tumors and 1 germinoma.

The experienced neuroradiologist gave the correct categorization of the pineal parenchymal tumors and germinomas based on conventional image features in 11/20 (55\% accuracy).

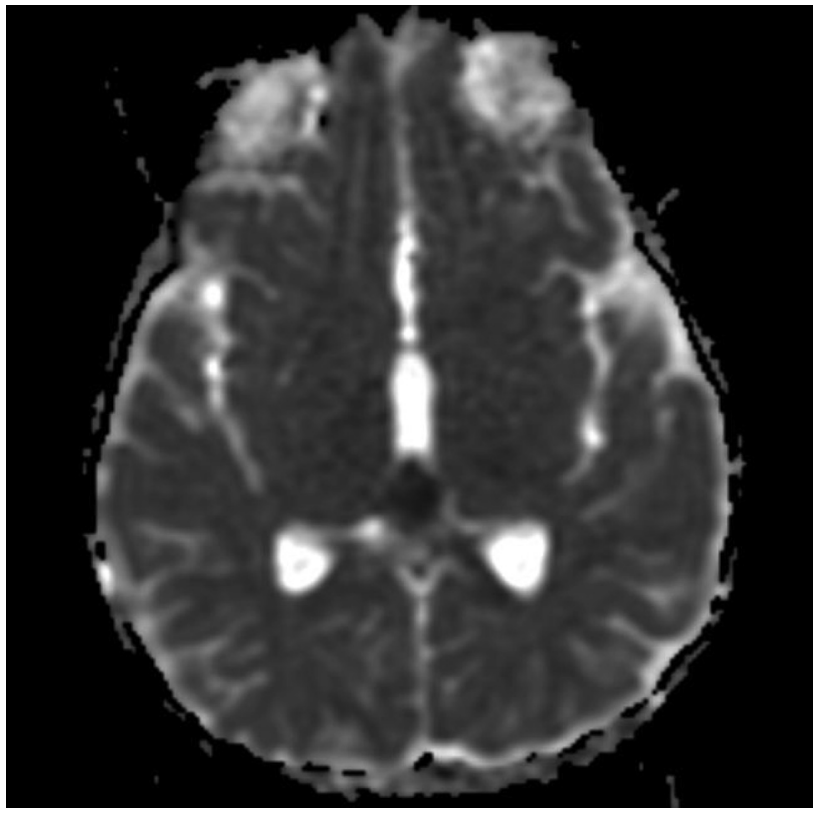

Fig 3. Pineoblastoma shows ADC value of $426.68 \times 10^{-6} \mathrm{~mm}^{2} / \mathrm{s}$.

\section{Discussion}

The spectrum of the pineal parenchymal tumors includes pineocytoma, PTPRs, PPTIDs, and pineoblastoma. Pineocytomas (WHO I) constitute $14 \%-30 \%$ of all pineal parenchymal tumors and can present in all ages, but most commonly present in adults from the third to sixth decades of age. ${ }^{3}$ Cysts and hemorrhage may be present but necrosis is rare. ${ }^{14}$ Gross total resection has been set as the standard treatment of this tumor, with favorable outcome. ${ }^{3}$ CSF dissemination rarely occurs ${ }^{2}$ and recurrences are uncommon. ${ }^{3}$

PPTIDs (WHO II or III) constitute of $20 \%-62 \%$ of pineal parenchymal tumors and occur mostly in adults, with slight female preponderance. ${ }^{3,14}$ Even though mitotic count is used to differentiate grades of PPTID, ${ }^{3}$ definite criteria for lowgrade and high-grade PPTID have not yet been established by the WHO. ${ }^{14}$ Management for high-grade PPTID is a combination of surgery, radiation, and chemotherapy, whereas the benefit of chemoradiation in low-grade PPTID is unclear. ${ }^{3}$ CSF dissemination is more common in high-grade $(36 \%)$ than in low-grade (7\%) PPTID. ${ }^{15}$

Pineoblastoma (WHO IV) is the most malignant type of the pineal-origin tumors; this type occurs commonly in children and constitutes $24 \%-50 \%$ of pineal parenchymal tumors. The histology of this tumor shows highly cellular, densely packed, patternless sheets of small cells with round to irregular nuclei and scant cytoplasm (high nuclear/cytoplasmic ratio). ${ }^{14}$ Extensive cystic change is rare. Treatment usually includes surgery, radiation, and chemotherapy. ${ }^{3} \mathrm{~A}$ high risk of leptomeningeal seeding was reported (45\%). ${ }^{16}$

PTPR can occur in both children and adults of a wide age range, from 5-66 years. Biologic behavior may lead to WHO classification of grade II or III, though definite criteria have yet to be determined. ${ }^{3,14}$ Histologically, this tumor is more densely cellular, and necrotic foci are often seen. ${ }^{14}$ No standard treatment has been established. ${ }^{3}$ A 7\% rate of CSF dissemination has been reported. ${ }^{17}$

Germinomas account for $1 \%-2 \%$ of all cranial neoplasms. 
Germinomas of the pineal region account for $50 \%-65 \%$ of intracranial germinomas, with male preponderance. Most of the patients are less than 20 years old. ${ }^{2}$ The histology shows large undifferentiated cells that resemble primordial germinal elements, prominent round vesicular, and centrally positioned nuclei with relative abundant cytoplasm. Necrosis is uncommon. ${ }^{14}$ Based on the abundance of cytoplasm, one might expect the ADCs of germinomas to be higher than those of the more densely cellular pineal cell tumors that have higher nuclear to cytoplasm ratios, which we found in our MR imaging.

As compared with the literature review, we found variable age distributions in both groups: $39.6-64.9$ years in pineocytomas, 45.6-49.2 years in PPTIDs, 1.5-31.6 years in PTPRs, $3.3-45.8$ years in pineoblastomas, and 9.3-20.6 years in germinomas. Our results showed a statistically significant age difference between the patients with germinomas (mean 13.7 years) versus pineal parenchymal tumors (29.4 years). Using a cutoff age of 21 years would have yielded a correct diagnosis of germinoma in all 7 patients, but would have been right in only 8 of $13(61.5 \%)$ of pineal cell tumors. We also found male preponderance in germinomas (6/7) and PPTIDs (2/2), and female preponderance in pineocytomas $(3 / 3)$. Reis et $\mathrm{al}^{4}$ reported 2 female cases of pineocytoma, and Komakula et $\mathrm{al}^{18}$ reported male predilection in PPTIDs (7/11). There were equal numbers in both sexes for pineoblastoma in our series. For the PTPR, we reported 1 female and 1 male, in contrast with the previous study, ${ }^{19}$ which reported 4 female cases. More cases are needed to assess sexual predilection.

The recent literature that suggests that the common pineal tumors have no pathognomonic imaging pattern ${ }^{4}$ was supported quantitatively by our result that showed no significant difference in T1- and T2-signal intensity values between pineal parenchymal tumors and germinomas. The pineocytomas, PPTIDs, and pineoblastomas were reported as showing isohypointensity on T1WI and isohyperintensity on T2WI. ${ }^{3,4,18}$ For the papillary tumors of the pineal region, variable signal intensity on T1WI and hyperintensity on T2WI can be seen. ${ }^{2}$ Chang et $\mathrm{al}^{19}$ and Vaghela et $\mathrm{al}^{20}$ reported hyperintensity on T1WI that may be related to the concentration of the protein content in the cystic spaces. Most of the pineal germinomas in Wang et $\mathrm{al}^{21}$ showed hypointensity on T1WI (19/22) and isointensity (26/32) on T2WI, whereas isointensity on both T1WI and T2WI was reported in 3 cases in Reis et al. ${ }^{4}$

Our results showed that most of the pineal region tumors were categorized as showing heterogeneous enhancement, which correlated with other studies. ${ }^{4,18,19}$ However, the groups showed no significant difference in coefficient of variation in T1WI, T2WI, and ADC images, which suggested that there was no significant difference in the degree of inhomogeneity.

All 20 patients in our study depicted variable degrees of enhancement, from mild to marked. The pineal parenchymal tumors showed nearly even distribution in degree of enhancement, while the previous studies reported strong enhancement in most of the PPTID cases, ${ }^{18}$ mild enhancement in papillary tumors, ${ }^{19}$ and avid enhancement in pineoblastoma cases. ${ }^{2}$ In contrast with our study, in which most of the germinomas were observed as mildly enhancing (57.1\%), Wang et $\mathrm{al}^{21}$ reported marked enhancement in most of the cases
$(28 / 32)$. This may be caused by the variations in the postcontrast delay in scan time. While we administer gadolinium and perform a T2-weighted sequence, and then do 2 to 3 postcontrast T1-weighted sequences, we graded the degree of enhancement on the immediate axial postgadolinium T1WI, not the subsequent coronal and sagittal scans.

We found a statistically significant higher mean ADC value in germinomas (mean ADC $1590.69 \times 10^{-6} \mathrm{~mm}^{2} / \mathrm{s} \pm$ $532.96 \times 10^{-6} \mathrm{~mm}^{2} / \mathrm{s}$; Fig 2) compared with pineal parenchymal tumors (mean ADC $883.58 \times 10^{-6} \mathrm{~mm}^{2} / \mathrm{s} \pm 317.48 \times$ $\left.10^{-6} \mathrm{~mm}^{2} / \mathrm{s} ; P=.002\right)$. Douglas-Akinwande et $\mathrm{al}^{22}$ also reported 11 cases of germinoma in which the solid portions showed 55\% normal diffusion (mean ADC $947.64 \times 10^{-6}$ $\mathrm{mm}^{2} / \mathrm{s}$ ), $36 \%$ decreased diffusion (mean ADC $694.71 \times 10^{-6}$ $\mathrm{mm}^{2} / \mathrm{s}$ ), and $9 \%$ increased diffusion (mean ADC $1172.30 \times$ $10^{-6} \mathrm{~mm}^{2} / \mathrm{s}$ ). Because our study placed the ROIs around the tumor border at the maximum diameter, which included both cystic and solid portions, it likely caused the higher ADC value than the previously mentioned study. The lower ADC value in pineal parenchymal tumors might be an effect from the low ADC value in pineoblastomas (ADC 375.63-1027.49 $\times 10^{-6}$ $\mathrm{mm}^{2} / \mathrm{s}$, mean ADC $\left.614.06 \pm 239.65 \times 10^{-6} \mathrm{~mm}^{2} / \mathrm{s}\right)($ Fig 3$)$. Low ADC value in the solid part of pineoblastomas has also been reported (mean ADC $512.2 \pm 24.4 \times 10^{-6} \mathrm{~mm}^{2} / \mathrm{s}$ ). ${ }^{23}$ Moreover, a negative correlation of the ADC value in pineal PNETs (medulloblastoma, PNET, pineoblastoma) and germ cell tumors was suggested. However, there was no significant difference in ADC values between these 2 in a previous report. ${ }^{24}$ The low ADC value in pineoblastoma might be explained by the high cellularity and high nuclear/cytoplasmic ratio of the tumor. Wide ranges of ADC values in germinomas might be caused by the difference amount in the cystic component and less attenuated tumor cellularity and lesser nuclear/cytoplasmic ratio as compared with pineoblastomas.

Data regarding ADC values of the pineocytoma, PPTID, and PTPR have yet to be established. Inoue et $\mathrm{al}^{25}$ and Vaghela et $\mathrm{al}^{20}$ reported ADC values in PTPRs $\left(600 \times 10^{-6} \mathrm{~mm}^{2} / \mathrm{s}\right.$ and $812 \times 10^{-6} \mathrm{~mm}^{2} / \mathrm{s}$, respectively). Our study demonstrated a higher ADC value for PTPRs (ADC 993.25-1296.42 $\times 10^{-6}$ $\mathrm{mm}^{2} / \mathrm{s}$, mean ADC $1144.83 \pm 214.37 \times 10^{-6} \mathrm{~mm}^{2} / \mathrm{s}$ ), which may be the result of the inclusion of the cystic component in our ROI. Komakula et $\mathrm{al}^{18}$ described 4 cases of PPTID as showing no restricted diffusion. In our study, we found an ADC value of $1123.63-1229.56 \times 10^{-6} \mathrm{~mm}^{2} / \mathrm{s}$ (mean ADC $\left.1180.34 \pm 53.36 \times 10^{-6} \mathrm{~mm}^{2} / \mathrm{s}\right)$ in pineocytomas and an ADC value of $904.14-1067.35 \times 10^{-6} \mathrm{~mm}^{2} / \mathrm{s}$ (mean ADC $985.75 \pm$ $\left.115.4 \times 10^{-6} \mathrm{~mm}^{2} / \mathrm{s}\right)$ in PPTIDs. A trend of decreased diffusion in PPTID, as compared with pineocytoma, was suspected because this may be correlated with a higher WHO grade. Further study in a larger population should be performed.

By setting a threshold value of $1250.00 \times 10^{-6} \mathrm{~mm}^{2} / \mathrm{s}$ for $\mathrm{ADC}$, we were able to predict the correct diagnosis in 17 of 19 pineal region lesions, doing better than the clinical impression of the experienced neuroradiologist basing his opinion on other imaging characteristics $(11 / 20)$. This value should be tested in follow-up studies to determine if it remains valid across other study samples.

The small number of patients limited our retrospective study; therefore, a larger study to evaluate applicability of the $1250.00 \times 10^{-6} \mathrm{~mm}^{2} / \mathrm{s}$ ADC for obtaining a differential diag- 
nosis of germinoma, pineocytoma, PPTID, PTPR, and pineoblastoma is suggested. Partial volume averaging at the tumorCSF interface and from thick sections may lead to inaccurately high ADC. Difference in b values can interfere in the measurement: A recent study reported a statistically significant lower ADC value with a b-value of 1000 seconds $/ \mathrm{mm}^{2}$ as compared with a b-value of 800 seconds $/ \mathrm{mm}^{2}(P<.01) .{ }^{26}$ Our study was also limited by the retrospective method, and some scan parameters could not be retrieved. Variable scanning parameters could have influenced our T1, T2, and ADC values. The assessment of enhancement was subjective and not quantitative. Also, the histopathology of tumors before 2007 must also be reviewed, because PPTID and PTPR were only recently recognized in the newer WHO classification in 2007. However, this would not affect our main intent in differentiating generically pineal cell versus germinoma tumors.

\section{Conclusions}

Germinomas showed higher ADC values than the pineal cell tumors $(P=.02)$, and the patients were younger. A threshold ADC value of $1250.00 \times 10^{-6} \mathrm{~mm}^{2} / \mathrm{s}$ encircling the entire tumor was useful in distinguishing between germinomas and pineal cell origin tumors, with $89.5 \%$ accuracy. Otherwise, there were no definitive imaging characteristics that distinguished pineal cell from germinoma pineal region tumors. The T1WI and T2WI intensity values, degree of heterogeneity, and enhancement did not differentiate the 2 .

\section{Acknowledgments}

We would like to express our gratitude to Professor John Boitnott, MD, Department of Pathology, and Gloria Vila, Data Base Administrator, Johns Hopkins Radiology at Mount Washington, Center for Imaging Informatics, for generating the patient lists.

\section{References}

1. Yousem DM, Grossman RI. Neoplasms of the brain. In: Yousem DM, Grossman RI, eds. Neuroradiology: The Requisites, 3rd ed., Philadelphia: Mosby;2010:94-98

2. Smith AB, Rushing EJ, Smirniotopoulos JG. From the archives of the AFIP: lesions of the pineal region: radiologic-pathologic correlation. Radiographics 2010;30:2001-20

3. Dahiya S, Perry A. Pineal tumors. Adv Anat Pathol 2010;17:419-27
4. Reis F, Faria AV, Zanardi VA, et al. Neuroimaging in pineal tumors. J Neuroimaging 2006;16:52-58

5. Konovalov AN, Pitskhelauri DI. Principles of treatment of the pineal region tumors. Surg Neurol 2003;59:250-68

6. Castillo M, Mukherji SK. Diffusion-weighted imaging in the evaluation of intracranial lesions. Semin Ultrasound CT MR 2000;21:405-16

7. DeLano MC, Cooper TG, Siebert JE, et al. High-b-value diffusion-weighted MR imaging of adult brain: image contrast and apparent diffusion coefficient map features. AJNR Am J Neuroradiol 2000;21:1830-36

8. Guo AC, Cummings TJ, Dash RC, et al. Lymphomas and high-grade astrocytomas: comparison of water diffusibility and histologic characteristics. Radiology 2002;224:177-83

9. Krabbe K, Gideon P, Wagn P, et al. MR diffusion imaging of human intracranial tumours. Neuroradiology 1997;39:483-89

10. Okamoto K, Ito J, Ishikawa K, et al. Diffusion-weighted echo-planar MR imaging in differential diagnosis of brain tumors and tumor-like conditions. Eur Radiol 2000;10:1342-50

11. Cartes-Zumelzu FW, Stavrou I, Castillo M, et al. Diffusion-weighted imaging in the assessment of brain abscesses therapy. AJNR Am J Neuroradiol 2004;25:1310-17

12. Guzman R, Barth A, Lovblad KO, et al. Use of diffusion-weighted magnetic resonance imaging in differentiating purulent brain processes from cystic brain tumors. J Neurosurg 2002;97:1101-07

13. Schaefer PW, Grant PE, Gonzalez RG. Diffusion-weighted MR imaging of the brain. Radiology 2000;217:331-45

14. Nakazato Y, Jouvet A, Scheithauer BW, et al. Tumors of the pineal region. In: Louis DN, Ohgaki H, Wiestler OD, et al., eds. WHO Classification of Tumors of the Central Nervous System. Lyon, France: IARC Press;2007:122-29

15. Fauchon F, Jouvet A, Paquis P, et al. Parenchymal pineal tumors: a clinicopathological study of 76 cases. Int J Radiat Oncol Biol Phys 2000;46:959-68

16. Chang SM, Lillis-Hearne PK, Larson DA, et al. Pineoblastoma in adults. Neurosurgery 1995;37:383-90, discussion 390-91

17. Fevre-Montange M, Hasselblatt M, Figarella-Branger D, et al. Prognosis and histopathologic features in papillary tumors of the pineal region: a retrospective multicenter study of 31 cases. J Neuropathol Exp Neurol 2006;65:1004-11

18. Komakula S, Warmuth-Metz M, Hildenbrand P, et al. Pineal parenchymal tumor of intermediate differentiation: imaging spectrum of an unusual tumor in 11 cases. Neuroradiology 2010;53:577-84.

19. Chang AH, Fuller GN, Debnam JM, et al. MR imaging of papillary tumor of the pineal region. AJNR Am J Neuroradiol 2008;29:187-89

20. Vaghela V, Radhakrishnan N, Radhakrishnan VV, et al. Advanced magnetic resonance imaging with histopathological correlation in papillary tumor of pineal region: report of a case and review of literature. Neurol India 2010; 58:928-32

21. Wang Y, Zou L, Gao B. Intracranial germinoma: clinical and MRI findings in 56 patients. Childs Nerv Syst 2010;26:1773-77

22. Douglas-Akinwande AC, Ying J, Momin Z, et al. Diffusion-weighted imaging characteristics of primary central nervous system germinoma with histopathologic correlation: a retrospective study. Acad Radiol 2009;16:1356-65

23. Gasparetto EL, Cruz Jr LC, Doring TM, et al. Diffusion-weighted MR images and pineoblastoma: diagnosis and follow-up. Arq Neuropsiquiatr 2008;66: $64-68$

24. Yamasaki F, Kurisu K, Satoh K, et al. Apparent diffusion coefficient of human brain tumors at MR imaging. Radiology 2005;235:985-91

25. Inoue T, Kumabe T, Kanamori M, et al. Papillary tumor of the pineal region: case report. Brain Tumor Pathol 2008;25:85-90

26. Steens SC, Admiraal-Behloul F, Schaap JA, et al. Reproducibility of brain ADC histograms. Eur Radiol 2004;14:425-30 